\title{
The culture of aviation security through the prism of sociological analysis
}

\author{
$M V$ Stryhul $^{1 *}, O A$ Khomeriki $^{1}, Y u I$ Yakovenko $^{1}, A K$ Yakovenko $^{1}$, and $Y u V$ Romanenko $^{1}$ \\ ${ }^{1}$ National Aviation University, 1 Liubomyra Huzara ave., Kyiv, 03058, Ukraine
}

\begin{abstract}
The aim of the article is to demonstrate the relevance of the usage of sociological knowledge for the development of aviation safety culture through the safety and security, Sociology of Safety and Sociology of Transport as an integral part of applying a systematic approach for strengthening the aviation safety. In the situation of globalization of the world, the structure of sociological knowledge in the XXI century is very branched. However, Ukraine has its own popular list of special and branch sociologies, which meets the specific challenges of the time of modernization of Ukrainian society. The goals of the industrial stage of its development stimulated the formation of Sociology of Labor, changing the focus of the goals of the economy from the basics of planning to market. That gave a powerful impact on the formation of Sociology of the Economics, the market, the individual, and so on. There were not identified the conditions, circumstances that should determine the application of the potential of sociology to comprehend any direction of human activity. Sociologists strive not to lose the integrity of reflection, as social science always gains more power, accumulating both empirical material and theoretical generalizations on significantly different aspects of social life, which can be taken into account in the development of each sociological industry. Therefore, security contains resistance to the Sociology of Safety, Sociology of Technology, Sociology of Transport, etc. Accumulation of such knowledge with necessity leads to synergistic effect and the growth of a culture of safety in aviation.
\end{abstract}

\section{Introduction}

In the so-called era of modern times began the rapid development of science and technology, which, in particular, resulted in the improvement of classical texts on the theory of knowledge and methods of scientific research, which contain many important recommendations for our contemporaries. The texts were created by a large number of authors of different centuries. These texts appeared in the form of rules for both research and acquaintance of colleagues with their results. Thus, for the XVII century a kind of summary at that time was the "Rules for the Guidance of the Mind", associated with the work of Descartes [1]. Rule number 1 is that the purpose of scientific studies should be formed in such a way that the human mind can make adequate judgments, if possible, all

\footnotetext{
* Corresponding author: maryna.stryhul@npp.nau.edu.ua
} 
the realities to which it is directed (in modern language it is the proclamation of a systematic approach). Rule number 2 is that you should deal only with those subjects about which the researcher's mind has obvious opportunities to achieve reliable knowledge (a competent approach). Rule number 3 is that in relation to such subjects it is necessary to identify not those features that are already known to others, but those that are first proposed by the researcher so clearly and obviously that colleagues should recognize because of their persuasiveness (mandatory validity of novelty of results in some theoretical or empirical way). As researchers in each field are focused on using not so much general as special methods, each or a group of researchers is forced to have both the ability to research and limit those additional competencies that are not general and special, but should be quite desirable. For this reason, such social and behavioral disciplines as Political Science, Psychology, Sociology or Humanities are taught in the Free Economic Zone.

The authors, remembering the classic rules, try to find innovative knowledge about aviation safety, without being on the basis of professional affiliation among certified experts in aviation technology and related infrastructure. Security experts are well aware of the popular saying: "the strength of the chain is in its weakest link", and therefore, if the factor in the accident in aviation is not technology, then turn the attention to people. Being patriots and members of the Sociological Association of Ukraine, in the XXI century we are concerned with a number of issues related to understanding the transformation processes in the homeland. They are under the constant influence of modernization of various circumstances, including both equipment and engineering personnel, who is obliged to master the equipment. Of course, all this affects the safety on engineers within their competence, and, accordingly, the authority in the world of the domestic aviation industry, but also the state as a whole. This patriotic concern is always common for Ukrainian scientists, but there is also a special concern for sociologists.

\section{Materials and methods}

Each subsequent study will further increase the importance of sociological knowledge in managing the modernization of Ukrainian society by improving not only science in general, but also in particular, sociological theory and methods of studying social change. The world practice of sociological research and discussion of their results at sociological congresses of different levels, has shown that the focus of modern professional sociologists is the concern of optimizing the self-reflection.

First, we should identify the factors of further institutionalization of sociology due to the expansion of researchers to study new areas or even areas of social action. Secondly, it is worth maintaining the reputation of sociology as a subject, science and profession (these words are from the title of almost the same legendary lecture by M. Weber in Munich, 1918), whose representatives should not contribute to the loss of prestige of their work and further strengthen the status of sociology as a useful science in the minds of members of civil society and public government. This should help scientists to invest in research on permanent social change. It should be mentioned to obtain empirical data is a mandatory stage of the research program, because it is speculatively difficult to accurately and reliably identify the nature and content of human activities in a particular field of social practice.

The aim of the article is to recognize the relevance of the use of sociological knowledge for the development of safety, sociology of safety, sociology of transport as an integral part of the application of a systematic approach for strengthening aviation safety in order to obtain new social content.

From statements of a general nature, move on to specific ones related to the aviation profile of the National Aviation University in the capital of Ukraine, where the authors are employees of the Department of Sociology and Political Science. Sociologists of the 
country are well aware that the relevant departments in specialized (technical, artistic, natural, sports, etc.) universities have an emphasis on the task of development and teaching exclusive sociology (Sociology of Architecture for construction students, Sociology of Medicine for medical students, Sociology of Army for cadets of military universities, etc. The meaning of this task is obvious. It is to outline the sociological aspects of human factor management in a particular area of human activity.

In fact, if the staff who has mastered the technique solve their current actual problems, then it is necessary to study systematically not only the state of the art, but also the state of staff. There is no doubt that a such task is performed by physicians or psychologists, anthropologists and so on. Sociologists have also proven their ability to justify their own subject of study in each area of human activity. We are convinced that the development of artificial intelligence increases the efficiency of assessment and management and certainly take into account the results of the work of social and behavioral sciences as long as people work next to robots or automated systems and so on.

It is that each subsequent study contributes to the growth of the importance of sociological knowledge in the management of modernization of Ukrainian society through the improvement not only of science in general, but also in particular, sociological theory and methods of studying social changes. The world practice of sociological research and discussion of their results at sociological congresses of different levels showed that the focus of modern professional sociologists is the concerns of optimizing self-reflection.

Keeping with the logic of expanding the content of this article from the general through the specific to the partial, it should be declared that the status of "partial" is also inherent in the development of aviation safety culture, where human management requires a broad scientific justification, including the disciplines of social and behavioral sciences. That is, thanks to the development of transport sociology is connected with other sociological branches. To understand the author's vision of these perspectives, it will be used the field concept of explaining the contradictions in the modernization of the structure of sociological knowledge, developed by P. Bourdieu [2]. The scientist came to the conclusion in the twentieth century that the most common characteristics, inherent in all social fields, are the features of competition, monopoly, and the balance of supply and demand. Therefore, the knowledge of these circumstances makes it possible to talk about a social field (science, literature, journalism, religion, as well as aviation, etc.), as a kind of market, which is already obvious to Ukrainian citizens. Bourdieu wrote [3] that within the field of science, "symbolic production" is carried out, which is defined as the production of knowledge and its main components, which are scientific truths. This field is a place of competition, the specific stake in which is a monopoly on scientific authority, designated as a technical ability and at the same time as a social power or monopoly on scientific competence, understood as a socially assigned to a certain individual ability to legitimately speak and act on behalf of science.

Similarly, for practitioners, for example, in the field of aviation, the concept of the field, according to P. Bourdieu [4], plays the role of a universal intermediary concept to explain the relationship between the external conditions of practices and their direct implementation. The intermediary function of the concept field is carried out by taking into account the laws of the development of the social system, as well as the circumstances (external and internal) regarding the existence of both an individual and social level. Since in sociology the structure of knowledge is divided into 1) theoretical sociology, 2) middlelevel theory, and 3) empirical basis of science, which should be generalized thanks to the theoretical optics of sociology, which is available in the middle-level theories. The ontological relevance of its application is justified by the fact that the process of globalization is essentially determined by the important role of transport and communications. Therefore, on the model of such a phenomenon as the proclamation of a 
complex science in the past centuries in the era of apogee on the eve of the industrial revolution. There is an era of expectation the dominance of the science of transport and communication as a supercomplex science and the era of the communication revolution as the key to the effective movement of speech, Linguistics and knowledge on the planet. Sociology of Transport appears as an unknown component of this new phenomenon next to the Economics of Transport, Transport Medicine, Legal Principles of Transport, and so on. Pilots' communication skills make the core of pilots' professional communication competence and play an important role in the process of flight operation [10].

Of course, the state of each science or cognitive practice depends on the ability of the subjects of this activity. Examples of this are not only a scientist, researcher, but also an expert or detective - a specialist in the investigation of crimes; or an investigator, for example, to identify the causes of accidents on transport. If the latter is responsible for obtaining evidence about the reliability of a certain version of the identification of a factor (suspect) and then providing them to the judicial authorities, then the situation is similar for a scientist, because only scientifically based new knowledge is positively perceived by contemporaries of innovations, as well as the authorities of investigative bodies. Sometimes the researcher or inquirer must submit their conclusions in a certain way to the authorities for individuals who must make a decision within their competence in the structure of state bodies, or vice versa, through a corporate conspiracy against themselves, that is, the inquirer, to appeal to the public, revealing publicly the abuse of managers who act only in their own or corporate interests. So, the publication of abuse (even the theft or loss of passengers ' luggage) or the incompetence of the relevant employees (even the regular postponement of flights) in scientific journalistic publications leads to a question that were mentioned, because it concerns the motivation of each of the three participants in these processes, according to the triad approach. For example, the motivation of the suspect in connection with the identified factor as an object of knowledge. The motivation of the researcher/inquirer as a subject of cognitive activity; finally, the motivation of individuals who later make decisions based on the results of research work after reporting, their decision not only legitimizes the conclusions, but also produces their actual meaning. The analogy of the triad in science is obvious. It is the social object and subject of research.

Since several examples of chains of three components have already been given above, this gives the reason to recall the details of such a well-known approach in world science as the triad approach. In the most general form, the fundamental triad can be represented as a structure consisting of one entity X (the carrier of the triad), a second entity Y (the reflector of the triad), and the relationship between them $\mathrm{f}$ (reflection) [5], more specifically for sociologists [6]. At the same time, if we talk about the chain and its three parts, when the middle connects the extreme, we recall a long-known thesis: the strength of the chain depends on the strength of the weakest link.

\section{Obvious triad in Sociology}

\subsection{Object and subject of research}

First of all, the expert community considers the conclusions of cognitive activity justified when they are presented, first, in an adequate theoretical context regarding the object and the subject of knowledge. Secondly, based on the use of such a method that has already allowed to obtain reliable search data. Thirdly, they cause an active discussion of their heuristic potential as a positive quality, and vice versa. Experts have popular response options. It is interesting, because it corresponds to the general line of the party's activity program, the management of an industry or institution, and so on. Secondly, it is 
interesting, but it is not relevant now, because there are no resources for further research, because there is a more relevant aspect, for example, even a safer one, rather than a resource one (a type of capital). Thirdly, it is not important, because it contradicts at this time the accepted worldview, scientific paradigm, or program for the development of something more general and tangential relative to the expected conclusions.

Thus, we note that the author's conclusions are based on the above obvious triad in sociology: 1) the object and 2) the subject of research, as well as 3) the consumer of the conclusions that are systematically related. Whatever the sociological branch, its object is individual, and its subject is circumstance related to the branch. The subject is the researcher and the consumer. The presence of the human is obvious. Consumers are always sensitive to potential risks and to external determinants of agents currently placed in the transport field. Their influence is always mediated by the specifics of the field in which the agents are. The logic of the actions of agents should be understood, according to P. Bourdieu, using the concept of "capital" [7]. So, the position of agents within the field depends on the volume and the relative weight of the types of capital they own, and therefore the relevance of sociologists' conclusions accounts on the calculation of symbolic capital in the field of their activity. (Logic and laws, location and struggle of forces operating within this field).

\subsection{Branches in Sociology}

Starting from such classical fields as sociology of labor, reading, education, etc., the success of these industries depended on the ability of stakeholders to contribute to an adequate preliminary description of the general population and qualitatively form a sample population, without prior empirical knowledge which scientists can not identify as an empirical stage of the study. This is very difficult in general, because the empirical object (for example, passengers) is not a clear structure, and we cannot see any interest from the authorities to determine this structure at the moment. Finally, the field of transport is dominated. It is more influential than money, although wealth is considered a spiritual force, but in essence it is an evil force, because by influencing people, it enslaves them through money and does not contribute to the search of truth. It is easier to achieve the desired result of innovation in management. For example, create the baggage tariff, or invent another tariff or tax, than to study the requests of all agents in this field. Thus, the prospects for the development of the Sociology of Transport depend on overcoming the risks associated with the three systemic components of the industry, which are both objective and purely subjective, sometimes gaining the status of a factor of insurmountable force.

The aim of the scientist's activity is to identify trends, and sometimes patterns and laws on the relationship between phenomena in nature and society, as each law reflects certain and at the same time general connections and relationships inherent in all phenomena of the genus, class, sphere. By nature, the laws indicate the necessary, essential, sustainable, repetitive. Since the law is discovered because it exists independently of human consciousness, the discovery of laws is the main task of every scientist and is the objective basis for the transformation of nature and society. There are general and partial laws, there is a dialectical relationship between them. General laws operate through specific, and partial laws are a manifestation of specific laws. This process scheme is quite universal and therefore can be applied in our reasoning to understand the development of aviation safety culture. So, first we start from the fact that the word "knowledge" is used to construct the general name: history, social science, tourism, etc., including security. Then on ensuring safety in aviation carry out reflection by means of special disciplines. Therefore, in this text of the article it is observed the place and role of Sociology of Transport in the management 
of the human factor as the creation and avoidance of risks in the transport sector in the example of aviation.

Currently, there are already fairly stable ideas about the structure of sociological knowledge, the areas in which researchers work, the set of theoretical concepts that they choose as basic (with the appropriate lexicon) to justify a particular research project. However, both the results of an individual project and the results of their whole still do not convince all colleagues from the social sciences department that within this workshop such a distinctive aspect of sociology as the production of empirical material through sociological methods leads to the formation of indisputable sociological laws.

Meanwhile, there is no discovery of laws that ultimately govern the formation, development and functioning of society as a complex social system as a whole, or at least its individual subsystem in the form of a social institution, such as transportation or aviation, according to the profile of this Congress. Therefore, we will not talk about the apologetic of sociology, but its self-critical evaluation. Omitting the inalienable and obvious word "sociology" in the title, the list of special or branch sociologies in the structure of sociological knowledge can take into account about a dozen or two, if we talk about the culture of safety in aviation.

\section{Discussion}

\subsection{A short mass event}

Let's start with a simple example of a relatively short-lived mass event that attracts the attention of sociologists. The media have now reported that, in autumn, 2020, ten of thousands of Jews, representing the Bratislava wing of Hasidism, are arriving in Oman via Kyiv by plane. They consider it their duty to visit the tomb of Tzaddik Nachman at least once in their life. Celebrating the New Year (Rosh Hashanah) near his grave on September 19,2020 , they believe that next year will be very happy, because this year will be another anniversary of the Tzaddik - 210 years since his death. Meanwhile, in 2010 was the classic anniversary of the Tzaddik - 200 years since his death, and therefore between Ukraine and Israel signed an agreement on mutual visa-free entry into the country to ensure a mass pilgrimage of Hasids to Ukraine. In 2019, there were about one hundred thousand Hasids in Uman.

It is obvious to sociologists that the mass movement of religious tourists gives grounds to mention a number of branch and special sociologies. Sociology of Religion understands the essence of the views of these people; Sociology of Conflicts helps to understand possible conflicts in the course of interpersonal and international interactions. Sociology of Tourism due to the fact that the interaction is a part of the provision of tourist services by tourist organizations. Sociology of Organizations understands the financially and social effective activity of numerous organizations involved in travel, in particular airlines. Sociology of Medicine helps to promote the prevention of mass diseases by studying the attitude of people wearing masks, etc. Sociology of Public Opinion considers the attitude of the masses to meet the requirements of the quarantine.

In the future we will consider a longer-term phenomenon: charter flights through the tourist season both in summer and winter, which differ not only in weather conditions and, accordingly the contents of luggage and clothing that may be lost or distorted during the flight. Mass thefts at airports are of interest not only to foreign scientists, but also to sociologists. Sociology of Crime is able to provide data on the social features of these events. Sociology of Stereotypes allows to distinguish social groups according to the style 
and way of life of people of certain small groups, and therefore we will mention Sociology of Small Groups, and Sociology of the Environment, Sociology of Lifestyle and so on.

At the end of this block of the article we will name general circumstances of modern life. They are called the following words: the Internet, the media, branding, professions, regions, advertising, marketing, business, labor, management, international relations, etc. Of course, they can justifiably get the word "Sociology".

\section{Conclusions}

Since the "Guidelines for Investigating the Role of the Human Factor in the Investigation of Aviation Incidents" (hereinafter - the Guidelines) are intended to assist state aviation inspectors of the National Bureau of Investigation of Incidents (hereinafter - NBRCA) in applying a systematic approach in the field of investigation of aviation accidents and incidents through the study of the human factor, it will be used such a summary document to complete the justification that the purpose of the article has been achieved. Of course, without quotations from this document we will not use it adequately.

«4.2. A person can be involved in an event in three cases: - 4.2.1. Directly contribute to the occurrence of an aviation accident by committing dangerous acts. This is usually the result of an error by operating staff, often referred to as an "operator, pilot, air traffic controller, user error"; - 4.2.2. A person works in dangerous working conditions or uses faulty (dangerous) machinery, means, equipment; - 4.2.3. Indirectly, ie "not directly" to promote the emergence or development of dangerous conditions as a result of dangerous actions long before the event or the creation of a hidden (latent) factor. This path shows the connection between dangerous human actions and conditions and emphasizes the need to carefully study all the probable causes and associated factors".

According to 4.5.2 "Latent failures are the result of a decision or action that took place long before the event occurred. The effects of latent factors can be hidden for a long time. Latent failures usually occur at the level of decision-making personnel, so people who signed distance from the aviation event in place and time. An example of a latent refusal is the decision to merge two companies without training to standardize their operating procedures. Such failures can occur at any level due to human error. For example, the implementation of policies that lead to a decrease in motivation or increase staff fatigue". The mistakes of the operator, pilot, air traffic controller, sociologist are still "terra incognito", but without going into the details of the subject, respectively, to the essence of the sociology of work or profession or personality, etc., we can confidently insist on identifying social factors of latent causes mistakes. A good example of this is the decision of senior management of the aviation administration or aviation entity. When allocating resources, management needs to find the optimal balance between safety and profits, which can usually lead to wrong decisions that will affect all levels of the system.

Since the analysis of the stages of institutionalization of Sociology of Safety in modern Western sociological thought has already been carried out $[9,37]$, our research on the place and role of sociology in enriching the culture of aviation safety is connected with global trends. Of course, the preconditions for the formation of Sociology of Security and social knowledge of security issues were presented in the works of the classics of sociological science. It is obvious that the first period of formation of the sociology of security was general, because its emergence took place against the background of the development of the Sociology of International Security as an independent scientific discipline in the 30-40s of the twentieth century. The second stage of the institutionalization of Sociology of Security is characterized by the expansion of ideas about the subjective dimension of security, the disclosure of social and cultural aspects of security or insecurity in the mass consciousness in a break with tradition and turbulence of social processes. The development of the 
Sociology of Security at the present (third) stage is characterized by the expansion of the definitions of the subject area, a new understanding of the security situation of people due to rapid changes in the environment of international relations, because Ukraine is persistent in Europe and the world.

Guided by the so-called Occam's blade: "Numquam ponenda est pluralitas sine necessitate" (diversity should not be assumed unnecessarily) [11], let us conclude Descartes' last rule. If in a number of things to be studied there is something that our the mind is not yet able to consider well enough, it is necessary to stop here and not to study other things that follow it, refraining from inappropriate work.

\section{References}

1. R. Dekart, Sochineniya, 2 (Mysl, Moscow, 1989) [Electronic resource] Available at http://gtmarket.ru/laboratory/basis/3958

2. P. N. Burd'e, Choses dites, 288 (Socio-Logos, Moscow, 1994)

3. P. Burd'e, Socziologiya politiki, 336 (Socio-Logos, Moscow, 1993)

4. P. Burd'ye, Praktichniy gluzd, 503 (Ukrayinskiy Centr Duhovnoyi Kultury, Kyiv, 2003)

5. M. Burgin, Vvedenie v sovremennuyu tochnuyu metodologiyu nauki, 134 (Nauka, Moscow, 1994)

6. M. Burgin, V. Kuzneczov, Sociology and Politology 1, 11-24 (1996)

7. P. Burd'e, Ekonomicheskaya Sociologiya 5, 60-75 (2002)

8. Metodichni rekomendacii shchodo doslidzhennya roli lyudskogo faktoru pid chas rozsliduvannya aviaciynih podiy ta incidentiv [Electronic resource] Available at http://www.nbaai.gov.ua/uploads/pdf/Human_factor.pdf.

9. L. Kalashnikova, Visnyk Kharkivskogo nacionalnogo universitetu im. V N Karazina. Seriya Socziologichni doslidzhennya suchasnogo suspilstva: metodologiya, teoriya, metody 37, 37-44 (2016)

10. O. Kovtun, N. Khaidari, T. Harmash, N. Melnyk, and S. Gnatyuk, CEUR Workshop Proc., 2588, CEUR-WS (2019)

11. W. Okkam, Novaya filosofskaya enciklopediya (Elektronnaya biblioteka IF RAN) [Electronic resource] Available 